\title{
Recent Changes in Labor Force Participation: Trend or Cycle?
}

\author{
Riccardo DiCecio, Economist \\ Charles S. Gascon, Research Support Coordinator
}

$\mathrm{T}$ he labor force is defined as the number of people employed and unemployed. The labor force participation rate (LFPR) is computed by dividing the labor force by the working-age population. The participation rate has both cyclical and secular components. During a recession, the participation rate typically declines as discouraged workers exit the labor force. Anecdotal evidence highlights this effect during the recent recession, explaining how the weak labor market has led job seekers to quit looking for work and persuaded students to prolong their schooling. ${ }^{1}$ However, it is not immediately clear how much of the recent decline in the participation rate is due solely to cyclical phenomena. Slowly evolving demographic changes are also affecting the participation rate. In this essay, we explain how to decompose the changes in the LFPR into a cyclical component (due to current economic conditions) and a long-run component (due to demographic shifts).

The table shows the decomposed changes in the LFPR across age groups. ${ }^{2}$ Column 2 reports the total change in the LFPR. Columns 3 through 8 show the total change attributed to each age group. The last two columns report the contribution attributed to changes in the LFPR and population shares. The decomposition reveals that changes in the share of the population considered "prime working age" ( 25 to 54 years of age) have been a main driver of the lower LFPR over the past decade (column 7). Even without any change in this group's LFPR, it is now a smaller segment of the total population, which alone has the effect of pulling down total LFPR. ${ }^{3}$ The table also highlights another wellknown trend in the LFPR: the increasing participation of older Americans since 1990 (column 5). ${ }^{4}$

\section{During a recession, the participation rate typically declines as discouraged workers exit the labor force.}

The bottom row of the table decomposes the 0.66 percent decline in the LFPR over the past three years, much of which is dominated by a smaller share $(-0.79$ percent) of the prime working-age population. Some evidence, however, substantiates recessionary causes. The LFPR of the prime working-age population has contributed negatively

\section{Decomposing the Percent Change in LFPR}

\begin{tabular}{|c|c|c|c|c|c|c|c|c|c|c|}
\hline & \multirow[b]{3}{*}{$(1)$} & \multirow[b]{3}{*}{ (2) } & \multicolumn{6}{|c|}{ Contribution to $\% \Delta$ LFPR } & \multicolumn{2}{|c|}{$\%$ of total contribution } \\
\hline & & & \multicolumn{3}{|c|}{$\Delta$ LFPR } & \multicolumn{3}{|c|}{$\Delta$ Population share } & \multirow[b]{2}{*}{ (9) } & \multirow[b]{2}{*}{ (10) } \\
\hline & & & (3) & (4) & (5) & (6) & (7) & (8) & & \\
\hline $1980-90$ & 66.53 & 2.76 & -0.13 & 2.72 & -0.72 & -3.06 & 4.27 & -0.31 & 31.85 & 68.15 \\
\hline $1990-2000$ & 67.08 & 0.55 & -0.24 & 0.31 & 0.62 & -1.06 & 0.70 & 0.22 & 37.13 & 62.87 \\
\hline 2007-09 & 65.37 & -0.66 & -0.40 & -0.21 & 0.42 & -0.12 & -0.79 & 0.45 & 42.91 & 57.09 \\
\hline
\end{tabular}

NOTE: Contributions to percent change may not sum to totals due to rounding. 
to the decline ( -0.21 percent), which is likely due to difficult labor market conditions. The LFPR of 16- to 24-year-olds has also driven the aggregate decline; however, greater returns to education appear to have encouraged more high school graduates to go to college since at least the 1980s.

As individuals reenter the labor force, a cyclical correction in the LFPR is likely, causing the unemployment rate to rise. If the past two recessions are any indication, this correction may be modest. Difficult labor market conditions may have forced many individuals to make long-term decisions, such as early retirement or pursuing advanced education, that may remove them from the labor force for some time.
1 See, for example, Murray, Sara. "Grads Head to College in Record Numbers." Wall Street Journal, April 28, 2010.

${ }^{2}$ As proposed by Hotchkiss, Julie L. "Changes in the Aggregate Labor Force Participation Rate." Federal Reserve Bank of Atlanta Economic Review, 2009, 94(4), pp. 1-6.

3 The 2000-09 average LFPRs by group were as follows: ages 16-24, 61.3 percent; ages 25-54, 83.1 percent; ages 55 and older, 36.5 percent.

${ }^{4}$ For additional details and for a discussion of trends in the LFPR by gender, see DiCecio, Riccardo; Engemann, Kristie, M.; Owyang, Michael T. and Wheeler, Christopher H. "Changing Trends in the Labor Force: A Survey." Federal Reserve Bank of St. Louis Review, January/February 2008, 90(1), pp. 47-62. 